\title{
Correction to: Prediction of urban water accumulation points and water accumulation process based on machine learning
}

\author{
Hongfa Wang $^{1} \cdot$ Yajuan Zhao $^{2} \cdot$ Yihong Zhou $^{1} \cdot$ Huiliang Wang ${ }^{1}$
}

Published online: 23 October 2021

๑) Springer-Verlag GmbH Germany, part of Springer Nature 2021

\section{Correction to: Earth Science Informatics}

https://doi.org/10.1007/s12145-021-00700-8

In the original published version of this article, the third author's family name was misspelled. The name should have been presented as "Yihong Zhou" instead of "Yihong Zhu". The name is now presented correctly above.

The original article has been corrected.

Publisher's note Springer Nature remains neutral with regard to jurisdictional claims in published maps and institutional affiliations.

The original article can be found online at https://doi.org/10.1007/ s12145-021-00700-8.

Huiliang Wang

wanghuiliang@zzu.edu.cn

1 College of Water Conservancy Engineering,

Zhengzhou University, Zhengzhou 450001, Henan,

People's Republic of China

2 Yongcheng Vocational College, Yongcheng 476600, Henan, People's Republic of China 